\title{
Água e pedra: texturas de um corpo social em mudança ${ }^{1}$
}

\author{
Ida Mara Freire ${ }^{2}$ \\ Universidade Federal de Santa Catarina, Florianópolis, Brasil \\ E-mail: idamara@ced.ufsc.br
}


Resumo

O texto descreve a videodança Stone Water. Salienta as texturas da sociedade sul-africana pós-apartheid a partir das imagens desse povo que caminha junto, de mãos dadas. Propõe a videodança como um ensaio de etnografia visual. Examina a noção de temporalidade presente na infância, na percepção do outro e na experiência com a cegueira.

Palavras-chave: Crianças. Cegueira. Videodança. Etnografia. África do Sul.
Abstract

In this text I describe my dance film Stone Water. I first of all, point out the textures of the post-apartheid South African society starting from the images of a people who walk together, hand in hand. Secondly, I propose the use of dance film as visual ethnography essay. Finally, I examine the notion of temporality in childhood, in the perception of the other, and in the experience of blindness.

Keywords: Children. Blindness. Dance film. Ethnography. South Africa.

ILHA 


\section{O tempo e a duração}

Para tudo há o momento, e tempo para cada coisa sob o céu: tempo de dar à luz e tempo de morrer; tempo de plantar e tempo de arrancar o que se plantou; tempo de matar e tempo de curar; tempo de destruir e tempo de construir; tempo de chorar e tempo de rir; tempo de lamentar e tempo de dançar; tempo de atirar pedras e tempo de juntar pedras; tempo de abraçar e tempo de evitar o abraço; tempo de procurar e tempo de perder; tempo de guardar e tempo de jogar fora; tempo de rasgar e tempo de costurar; tempo de calar e tempo de falar; tempo de amar e tempo de odiar; tempo de guerra e tempo de paz.

Eclesiastes 3:1-8.

\section{Tempo de chorar...}

m 2008, fiz minha primeira visita à África do Sul, quando esti-
ve no museu de Hector Peterson, localizado em Soweto, e me emocionei ao entrar num jardim de pedras, com nomes gravados em pequenas placas de mármores das centenas de crianças e jovens que foram mortas durante o período do apartheid. Na frente desse museu há um monumento com pedras talhadas em meio a uma fonte de água 
cristalina. O guia esclarece: as pedras simbolizam a defesa por parte das crianças; e a água, as lágrimas de dor. Essa experiência marcou meu coração com uma indagação: Amamos as crianças?

\section{Tempo de juntar pedras...}

Essa pergunta me motivou a voltar ao solo sul-africano em 2011, acompanhada de minha pequena para viver por um ano na Cidade do Cabo; retornamos dessa viagem no final de janeiro de 2012. Uma jornada de quatro estações. Semeamos, cultivamos, colhemos e saboreamos. Nem sempre nessa ordem, mas foi uma experiência completa. Essa completude pode ser explicitada na percepção de que o todo é bem mais que a soma das partes. E que determinadas partes contêm o todo. Talvez um exemplo disso se mostre na realização de uma das nossas últimas ações naquele país, a saber, a realização de uma videodança.

\section{Tempo de dançar...}

Stone Water. 2012. Cidade do Cabo. África do Sul. Direção, Câmera e Edição: James Tayler. Assistente de Produção: Tamara Roberts. Elenco: Crianças da Gingerbread House: Excellence Olulope, Isabella Manshield, Kamile Hannah Freire, Logan Toni Morgan, Taybah Blommetje. Dançarinos da Cape Town Society for the Blind: Carmen Coetzee, Ida Mara Freire, Marisa Teles, Marshal Coetzee, Nettie Coetzee, Noxolo Qongqo, Peter Nolte, Sandra Dreye, Tamara Roberts, Silulani Groxokogxokwana, Vanessa Davis, Vincint Daniels. Trilha Sonora: Bob McFerrin: Circlesongs 6, Circlesongs; Gustavo Santolalla: Negrosantolallismo; Phillip Miller: Siyaya, Rewind Cantata; UAKIT: Thunder, I Ching. Duração: 8 minutos.

A videodança intitulada Stone Water (Pedra água), apresentada durante o II Colóquio Antropologias em Performance, tem como imagens iniciais água e pedras de uma praia da Cidade do Cabo. Sobreposta a tais imagens, ouve-se Siyaya, interpretada pelo coro, durante a cantata Rewind, composta por Phillip Miller. Siyaya é uma das canções que acompanham o toyi-toyi, a ritualística dança de guerra, popularizada durante o período do apartheid, ao ser dançada em situação de con- 
fronto e enfrentamento. As imagens seguintes apresentam cenas de uma oficina de dança oferecida na Cape Town Society for the Blind (Sociedade das Pessoas com Cegueira da Cidade do Cabo). As imagens editadas das mãos tocando pedaços de tecidos com diferentes texturas intercalam com as imagens das faces, dos gestos e dos corpos dos jovens e dos adultos em movimento, demonstrando que a pluralidade é a lei da terra, como nos adverte Arendt (1992, p. 17):

Nada e ninguém existe neste mundo cujo próprio ser não pressuponha um espectador. Em outras palavras, nada do que é, à medida que aparece, existe no singular; tudo que é, é, próprio para ser percebido por alguém. Não o Homem, mas os homens que habitam este planeta.

A voz em off ressoa o poema de Eclesiastes 3 e evidencia a intensa noção de temporalidade latente da sociedade sul-africana pós-apartheid. O murmúrio do mar contracena com as imagens da água na praia com suas pedras, que numa ação em espiral entrelaçam as imagens de cinco meninas com quatro a seis anos de idade, entre elas está a minha filha. Elas brincam junto os jogos e os cânticos infantis aprendidos com as crianças do povo Xhosa. São crianças cujas texturas de cabelos e cor da pele se diferenciam entre si. Tal cena, impensada 20 anos atrás, testemunha que o país mudou. A videodança, ao apresentar as imagens dessas paisagens marítimas e humanas embaladas com a sonoridade que lhes é peculiar, convida aquele e aquela que as veem a dançar, brincar e indagar sobre o tempo, a infância, a percepção do outro e a experiência com a cegueira.

A imagem registrada em vídeo torna-se, assim, uma escolha paradoxal do ver e do não ver. Pois o dançar com as pessoas com cegueira me propõe uma constante pergunta: o que estou a ver? Pois, quando estou a ver, foco e deixo de ver o que está à margem. Então faço aqui uma opção deliberada de desfocar. Usar os recursos da edição para fazer o que os olhos "humanos" não parecem capazes de fazer, mas podem ver. Uma provocação para aqueles dotados da visão. Afinal, quem tem olhos veja! Atente-se para as imagens sobrepostas, as texturas, os movimentos repetitivos de uma mesma ação, a inversão, a velocidade, ora rápida, ora lenta. Sonhe com os olhos abertos diante 
da luminosidade e a imagem de qualidade onírica. Perceba a profundidade, os contornos, os volumes propostos nas imagens dos corpos. Crie sua própria dança diante daquilo que oferece movimento, corpo, gestos, sonoridade, cenário, iluminação. Luz, câmera, ação!

\section{Tempo de abraçar...}

A noção de corpo social aqui empregada é inspirada no estudo de Jacques Derrida (2005) acerca do perdão. O texto em si foi um mapa que orientou caminhos, sugeriu rotas, indicou lugares, sinalizou percursos, facilitou trajetórias e acompanhou jornadas. O corpo social é mencionado quando o autor comenta acerca da palavra "reconciliação" com vistas à reconstituição do corpo nacional sul-africano. O gesto que simbolizou essa busca de reconciliação está na descrição autobiográfica de Nelson Rolihlahla Mandela (1997), quando escreve sobre o polêmico debate transmitido pela televisão com o oponente De Klerk:

O senhor é um daqueles com que conto, vamos ter que enfrentar o problema desse país juntos. Neste instante, peguei-lhe a mão e disse: orgulho-me de segurar sua mão para que sigamos adiante. [...] Eu queria um verdadeiro governo de unidade nacional [e...]. Em cada ocasião, eu dizia que todos os sul-africanos agora deviam se unir, segurando as mãos uns dos outros e dizendo "somos um único país, uma única nação, um único povo caminhando juntos em direção ao futuro" (Mandela apud Derrida, 2005, p. 60-61).

O que chama a minha atenção nessa fala é esse "segurar as mãos e caminhar juntos". Pois foi caminhando diariamente pelas ruas que me defrontei com os paradoxos da reconciliação e da noção de "unidade" e corpo social sul-africano. E foi nesse caminhar e dançar junto que vislumbrei a reconciliação. Ao compor a videodança Stone Water, mesclei o estilo documentário com uma explícita vertente sociocultural e o estilo experimental (Bordwell e Thompson, 2010). Sua narrativa, criada no caminhar diário de mãos dadas com a minha filha, sustenta a proposição de uma etnografia visual (Pink, 2001). O enfoque estético foi pensado com a intenção de buscar uma leveza para tratarmos de 
temas e episódios, tais como a impossibilidade de brincar junto; a cegueira e as mutilações durante o apartheid; a morte de jovens e crianças e o massacre Trojan Horse (Cavalo de Troia); a dança e o confronto do toyi-toyi; o ver e o não ver; o perdão e a reconciliação, e as ações que decerto coincidem em profundidade com um discurso literalmente idêntico de Nelson Mandela e de Desmond Tutu que diz da liberdade e da liberação dos brancos tanto quanto dos negros, como examina Derrida (2005, p. 57).

\section{Tempo de curar...}

A questão central da videodança é forjada no entrelaçamento do mundo do adulto e do mundo da criança, e, como cada um a sua maneira, explora o tempo, as relações, o "caminhar junto" e as "mãos dadas". Esses gestos que tocam o chão e que tocam o ser um do outro mostram que a superfície da pele, as pontas dos dedos são sustentadas por uma memória intercorporal. Hannah Arendt (2000, p. 247) nos ensina que

a educação é o ponto em que decidimos se amamos o mundo o bastante para assumirmos a responsabilidade por ele e, tal gesto, salvá-lo da ruína que seria inevitável não fosse a renovação e a vinda dos novos e dos jovens. A educação é, também, onde decidimos se amamos nossas crianças o bastante para não expulsá-las de nosso mundo e abandoná-las a seus próprios recursos, e tampouco arrancar de suas mãos a oportunidade de empreender alguma coisa nova e imprevista para nós, preparando-as em vez disso com antecedência para a tarefa de renovar um mundo comum.

Stone Water, ao ter como atores-dançarinos adultos com cegueira e crianças de diversas culturas, indaga tanto acerca da memória daquele que foi criança durante o período do apartheid quanto das crianças que paradoxalmente trazem no tempo presente a possibilidade de um amanhã. Seria, então, esse brincar junto que sustentaria o caminhar e o dançar junto, e o manter as mãos dadas até as últimas consequências? 


\section{Tempo de procurar...}

A proposição da videodança como um ensaio de uma etnografia visual se pauta em um trabalho de campo que busca entender como o significado é derivado do movimento do corpo que dança, como a estrutura de um evento deve ser entendida para derivar o significado disso, daí a necessidade de entender as atividades que geram sistemas de movimento e como e por quem é julgado o movimento, como sugere Adrienne Kaeppler (1999). Para fazer isso, seguimos o que essa autora recomenda: 1) olhar, observar o conteúdo do movimento e seus contextos; 2 ) aprender o idioma do grupo pesquisado, que, além de ser importante para a comunicação, explicita ênfases linguísticas e também fornece chaves a ênfases culturais ou sociais, além de a estrutura do idioma poder ainda ser a chave de um movimento e de outras estruturas; 3 ) gravar a informação em uma variedade de modos (notas pessoais, notação de movimento, gravação de filme/vídeo das performances em seus contextos); e 4) fazer análises preliminares de sua própria observação e participação, como também atentar para o olhar dos artistas e dos espectadores.

No que diz respeito à relação entre crítica e etnografia, Sally Banes (1994) aponta que ambas compartilham da mesma tarefa intelectual: o papel de traduzir. No entanto, essa tradução não está entre duas linguagens, mas entre experiência e linguagem, entre experiência e página. A experiência a ser escrita e a escrita em si mesma, ou o evento e sua representação. Algumas perguntas fazem-se necessárias, por exemplo, o que caracteriza essa experiência? Quem realiza? Quando e onde a experiência acontece? A autora comenta que a maior diferença entre etnógrafos e críticos de dança está onde a pesquisa acontece. O etnógrafo estuda o outro e também o cotidiano, o que leva à diferença de métodos de pesquisa. O trabalho de campo, observação participante, leva o etnógrafo a aprender uma língua estrangeira, viajar em diferentes lugares e culturas distantes, viver um ou dois anos em circunstâncias difíceis. Essa leitura sugere que, como críticos de dança, nós devemos atuar mais como informantes desse nosso mundo diverso e plural. 
E, assim, o caminhar pelas ruas da Cidade do Cabo consolidou a aproximação com a pesquisa etnográfica. Jennie Klein (2010), ao citar Michele de Certeau, comenta que, mais que um prazer, o caminhar tem o poder de remapear uma geografia hegemônica da cidade, representar uma estética ou uma intervenção política e reconectar o corpo do caminhante, andarilho, com a paisagem na qual se movimenta. Isso pode ser revolucionário ou meramente restaurativo; um tempo de pensamento produtivo e reflexão pode ocorrer como resultado de mover-se através do espaço. A autora descreve o caminhar como uma intervenção, discute o caminhar como comunidade, refere-se ao caminhar virtual e termina o artigo com o caminhar como uma descoberta. Desse modo, caminho com o intuito de produzir uma videodança que possa interessar e expressar um conhecimento etnográfico (Pink, $2001)$ e escrevo:

Moramos num pequeno apartamento no bairro chamado sugestivamente Observatory [Observatório], aqui conhecido como Observatry ou Obz!. Da nossa varanda temos vista para a montanha, um prédio de residência estudantil em construção, com dois guindastes que ocupam o pensamento da pequena durante o café da manhã. Atentamos para o teto triangular da igreja evangélica. Há um prédio pintado de cinza claro, que aos olhos da pequena parece um castelo, lá ficam o supermercado, a farmácia, o caixa eletrônico, alguns restaurantes, lojas e serviços. Um pouco mais para a esquerda, estão o Hospital Universitário e também o Hospital do Coração, dito, por alguns, o melhor do país, no que diz respeito aos transplantes e a outras cirurgias nesse órgão fonte de nossos afetos que nos ajuda a lidar com tantos desafetos. Seguindo a pé pela Main Road, no lado esquerdo, há um campo de futebol que também abriga nos dias quentes e secos alguns sem-tetos. Nos dias de chuva a pequena se preocupa e pergunta: Onde estão as pessoas que vivem aqui? Atravessamos o viaduto de uma rodovia e temos uma escola de ensino médio, pela manhã sempre nos deparamos com pequenas nuvens de adolescentes uniformizados em cores azul, as meninas de saias, cabelos impecavelmente trançados, marcando suas identidades; os meninos de calças cumpridas tentam, a sua maneira, achar seu lugar no mundo. Se observamos 
mais ao final da rua da escola, veremos uma mesquita. Continuando pela Main Road, passamos na frente da Igreja de Jesus Cristo dos Últimos Dias. Atravessamos mais uma quadra e nos deparamos com o Campus de Tecnologia da UCT [Universidade da Cidade do Cabo] e um prédio residencial. Já começamos a entrar no centro comercial de Mowbray, bairro onde fica a escola da pequena. Nessa região há biblioteca, bares, bancos, delegacia de polícia, farmácia, supermercado, dezenas de salão de beleza masculino e feminino, onde estão disponíveis vários tipos de penteados, estilos de tranças, lojas que vendem roupas, alimentos de diversos lugares da África, pois ali há uma concentração de pessoas de Gana, Angola, Nigéria, Camarões, Congo; os rapazes donos da Lan House, por exemplo, são moçambicanos. Quando passamos na lavanderia onde levamos nossa roupa, por ali já somos conhecidas, as pessoas nos cumprimentam, fazem brincadeiras com a pequena. Quando passamos felizes, fazem um comentário animador; se passamos zangadas, não perdem a oportunidade de nos dar um conselho. Para chegarmos na escola da pequena, cortarmos caminho entrando numa pequena rua, e nesse caminho há um teatro comunitário e uma ONG [Organização Não Governamental]. Chegamos no terminal dos táxis - como já comentei numa postagem anterior, os táxis, aqui são micro-ônibus, o meio de transporte mais rápido e barato para se locomover. Para nós ainda é uma experiência singular, alguns cobram a passagem da pequena, outros não. É costume, ao sair do mercado, o cobrador atravessar a rua e me ajudar a carregar as sacolas. A conversação entre cobrador e passageiro pode ser rude algumas vezes, principalmente quando há três passageiros bem sentados num banco e o cobrador quer que sente mais um por ali. Dois meses atrás, houve uma paralisação de três dias, e vi muita gente andando a pé. Os motoristas e os cobradores exigiam melhores condições de trabalho e organização do transporte coletivo. A pequena já inclui em suas brincadeiras o chamado dos cobradores, que gritam a direção em que vão, buzinam, convidam para sua viagem, cujo destino com certeza não é a ilha da fantasia. Mas, pelo contrário, geralmente é uma township, bairros com concentração da população negra e indiana com baixa renda, mas também de uma emergente classe média que prefere por ali ficar. Pelas ruas há carros, caminhões, 
ônibus de um ou dois andares bem coloridos, bicicletas e motos. Os carros, de diferentes tamanhos, expressam o gosto de uns e orçamentos de outros, os modelos que vão do popular ao smart, que ganha na preferência da pequena. Sábado pela manhã resolvemos ir ao Shopping Center em Claremont. Enquanto caminhávamos, um carro esporte com duas mulheres brancas parou e elas ofereceram carona para duas jovens negras que esperavam pelo micro-ônibus, elas desconfiadamente entraram no carro, após insistência. Há quem opta pelos trilhos e ainda aquelas, como nós, que caminham. Após deixar a pequena em sua escola em Mowbray, sigo até a UCT, pelo bairro residencial Rosebank, ao passar em frente à Igreja Metodista, que frequentamos aos domingos, caminho na rua lateral e me aproximo do bairro Rodenbosh, perto do teatro Baxter, no campus da área sul, tem o Faculdade de Música e, como parte dessa, o Departamento de Dança. Finalmente, chego ao meu destino e aí a caminhada começa a transformar-se em dança, em palavras, em reflexão sobre a poética do espaço. De quadra em quadra caminho no terreno sul-africano esboçando possibilidades de uma fenomenologia do redondo. (Postagem no blog, quarta-feira, 27 de abril de 2011)

\section{Tempo de construir...}

Ao esboçar o storyboard para a videodança, tive como roteiro a seguinte narrativa:

Caminho pela praia ao entardecer. Crianças de culturas diferentes brincam juntas. Anoitece. Escuta-se o som das ondas quebrando-se nas pedras à beira-mar. O dia se inicia sem que se amanheça. Apartheid. Caminho pelas praias. Vejo placas indicando proibição de permanência de pessoas de cor. Uma criança procura por sua infância. Caminho pelas ruas. Observo um grupo de oito trabalhadores uniformizados de azuis, eles dançam toyi-toyi na frente da casa do presidente em exercício. Caminho pelas escolas. Soweto. Adolescentes protestam, dançam toyi-toyi, querem aprender em sua própria língua. Resistência. Prisão. Mandela. Uxolo. Escuto as vozes do silêncio. Tutu. Ubuntu. TRC - Comissão Verdade e Reconciliação. Mães que choram por suas crianças que se 
foram. Cavalo de Troia. Procuro. Geração perdida? Vago. A cegueira me guia. Tateio. Reconciliação. Amanhece, embora a noite não tenha se dissipado por completo. Encontro. Crianças de culturas diferentes brincam juntas. Estrelas.

O cenário da videodança envolveu três locais distintos: a praia, a escola da pequena e a sociedade de apoio às pessoas com cegueira. A praia. Freedom Day. Aproveitamos o feriado nacional e o dia ensolarado para conhecer os pontos turísticos da Cidade do Cabo. E no segundo andar do ônibus vermelho, com fones de ouvido, escutávamos a descrição eletrônica, em inglês, das belezas naturais da Table Mountain (Montanha Mesa), que em uma de suas encostas o mar desenha praias, cujo acesso em algumas delas era vedado às pessoas negras ou de cor no período do apartheid. A escola. Gingerbread House foi a escola multicultural que a pequena frequentou durante esse ano que passamos lá. Localizado no movimentado bairro de Mowbray, esse centro de educação e cuidado atendia crianças de 6 meses a 6 anos. A Cape Town Society for the Blind (CTSB) tem como associados jovens e adultos com cegueira e desenvolve uma série de atividades culturais e profissionais com vistas ao desenvolvimento social. A filmagem toda foi realizada num mesmo dia, em seus respectivos ambientes. As cenas com as pessoas com cegueira foram capturadas numa oficina intensiva de dança oferecida na instituição. E as imagens das brincadeiras das crianças foram capturadas após ensaios em dias diferentes e marcações de cenas. As imagens da água e das pedras foram capturadas numa praia nos arredores da Cidade do Cabo. Referente à iluminação, algumas sequências tiveram como efeito a criação de uma atmosfera onírica, por exemplo, as cenas das crianças correndo em círculos. A ideia do amanhecer também estava explícita.

A intenção de produzir a videodança já presente no plano de estudo permitiu que as parcerias para realizar o trabalho fossem se construindo passo a passo. Por exemplo, foi durante o Seminário Film $\theta$ Dance, organizado pelo Gordon Institute for Performing and Creative Arts (GIPCA), do Departamento de Drama da UCT, que conheci James Tayler. A apresentação de um dos seus filmes envolvendo pessoas com surdez chamou a minha atenção; a qualidade da edição e o tratamento 
das imagens marcavam com sensibilidade sua percepção do outro. A assistente de produção, Tamara Roberts, era uma estudante do curso de Dança, interessadíssima no trabalho com as pessoas com necessidades especiais. Desde a primeira visita, quando apresentei uma comunicação oral no Confluences 5, evento promovido pelo Departamento de Dança da UCT, esse Departamento me acolheu como professora visitante. A participação de Tamara foi de suma importância, pois, dentre muitas atividades, me auxiliou nos ensaios com as crianças, no trabalho na CTSB. Ela, por falar Afrikaans, traduzia as instruções que eu dava durante a oficina. No que se refere às crianças, a escolha pela participação das cinco meninas na videodança teve como critério primeiro a amizade entre elas, segundo que evidenciasse a diversidade cultural e, por último, que as pessoas responsáveis autorizassem a filmagem. $\mathrm{Na}$ instituição de apoio às pessoas com cegueira, os critérios foram a participação na oficina intensiva de dança e a assinatura do Termo de Livre Consentimento para as filmagens e o uso do material para difusão e divulgação.

Pode parecer, nessa breve apresentação, que as pessoas envolvidas na realização da videodança posam apenas como meras figurantes. Talvez seja aqui que se contraponha com mais evidência a crítica de que uma videodança não poderia caracterizar-se como um material etnográfico, em virtude de não ser uma imagem "pura" sem edição, como discute Pink (2001, p. 79). Nessa discussão, adiciono que cada participante, em sua singularidade, contribuiu à sua maneira para explicitar a pluralidade e a complexidade da sociedade sul-africana. Exemplificando, a alteridade era exercida tanto na íntima relação com minha filha quanto na relação ética do não ver e ser visto que as pessoas com cegueira nos convidam a refletir; ou ainda, no invisível confronto das perspectivas discordantes do roteiro com o editor sul-africano de origem europeia; e, também, na lembrança sutil de um episódio doloroso, evocado na simples participação de uma das meninas que atualmente moram na casa vizinha, onde anos atrás aconteceu a morte de uma criança durante o massacre conhecido como Trojan Horse (Cavalo de Troia). De certo modo, Stone Water busca encenar uma estética do silêncio. No diálogo com Merleau-Ponty (2002, p. 168, grifo do autor), percebo que 
O corpo do outro está diante de mim - mas, quanto a ele, leva uma singular existência: entre mim que penso e esse corpo, ou melhor, junto de mim, a meu lado, ele é como uma réplica de mim mesmo, um duplo errante, ele antes freqüenta meus arredores do que neles aparece, ele é a resposta inopinada que recebo de alguma parte, como se, por milagre, as coisas se pusessem a dizer meus pensamentos, é sempre para mim que elas seriam pensamentos, é sempre para mim que elas seriam pensantes e falantes, uma vez que são coisas e eu sou eu. O outro, a meus olhos, está portanto sempre à margem do que vejo, ouço, está a meu lado, está a meu lado ou atrás de mim, não está nesse lugar que meu olhar esmaga e esvazia de todo 'interior'. Todo outro é um outro eu mesmo.

Como as texturas e os aromas se constituíram estímulos para o movimento? A proposição de uma oficina acerca das memórias corporais que são despertadas a partir do toque e de determinada textura e associadas a um aroma específico provocou gestos inesperados que se transformaram em dança. Os movimentos davam formas às palavras que surgiam da proposição do exercício de improviso de um encontro matinal entre uma pessoa que vê e descreve como está vivendo aquele dia, tendo como parâmetro suas experiências visuais; ela fala então de sua percepção do dia ensolarado com suas cores diáfanas, por outro lado, ela se delicia ao ouvir a descrição saborosa da textura aveludada do café com leite que seu amigo não visual lhe narra, descrição que deixaria qualquer barista inspirado. Na experiência do diálogo, como examina Merleau-Ponty (2002, p. 174),

a fala do outro vem tocar em nós nossas significações, e nossa fala vai, como o atestam as respostas, tocar nele suas significações, invadimo-nos um ao outro na medida em que pertencemos ao mesmo mundo cultural, e em primeiro lugar à mesma língua, e na medida em que meus atos de expressão e os do outro pertencem à mesma instituição.

O exercício dramatúrgico intitulado de rasas boxes fez lembrar que há tempo para toda emoção na superfície da terra. As brincadeiras e os jogos infantis apresentados na videodança foram escolhidos pela 
pequena Hannah. Ela chegava a nossa casa e me ensinava as brincadeiras que aprendia com suas amigas que ela chamava de povo Xhosa. Tais jogos, presentes no universo infantil sul-africano, têm o corpo como seu principal brinquedo. Acompanhadas de canções que misturam palavras das línguas inglesa e Xhosa, e marcam o ritmo, gestos imitativos e sequenciais, e toque das mãos, as brincadeiras explicitam um "brincar junto".

\section{Tempo de costurar...}

Há um minuto do mundo que passa, é preciso pintá-lo em sua realidade. [...] Tenho meu motivo, dizia Cézanne, e explicava que a paisagem deve ser abraçada nem muito acima nem muito abaixo, ou ainda: recuperada vivia numa rede que nada deixa passar. Então ele atacava seu quadro por todos os lados ao mesmo tempo, cercava de manchas coloridas o primeiro traço de carvão, o esqueleto geológico. A imagem saturava-se, ligava-se, desenhavase, equilibrava-se tudo chegava à maturidade ao mesmo tempo. A paisagem, ele dizia, pensa-se em mim e eu sou sua consciência. (Merleau-Ponty, 2004, p. 133)

Essa descrição feita por Merleau-Ponty acerca do trabalho de expressão de Paul Cézanne inspira escrever sobre o processo de composição das cenas para criar a videodança, pois esse processo se pautou em várias conversas de assuntos diversos, dentre eles, a noção fenomenológica, aqui já mencionada, que a parte contém o todo e que o todo é mais que a soma das partes; a proposição do movimento em espiral entre as cenas das crianças e os dançarinos com cegueira, a imagem das pedras e a água como transição. Mas parece ter sido o poema de Eclesiastes que deu o estalo para a edição final, atuou como um roteiro que possibilitou pensar a ordem das imagens com a ordem das frases que compõem um poema.

A sonoridade é um aspecto importante na edição da videodança, pois nela se identifica a unificação das cenas. Outro destaque está, principalmente ao coreografar e dançar com pessoas com cegueira, em ter em mente que elas são também o público-alvo. Nesse sentido, ainda que eu saiba que as imagens serão descritas para elas, gosto de 
pensar que elas podem ter uma experiência direta com aquilo que estão a ouvir e que isso desperta nelas a curiosidade a ponto de a descrição complementar o que elas estão a ouvir. Essa escuta sonora da leitura do poema de Eclesiastes 3:1-8; as vozes das pessoas conversando, que podem ser delas mesmas; o murmúrio das ondas do mar; as vozes das crianças a brincarem; a trilha sonora composta de músicas que fizeram parte da oficina; a abertura do filme com a canção Siyaya, cuja interpretação do coro recorda com força e beleza momentos de um povo que caminha unido no canto, na dança e na luta; o volume do som, ora alto, ora baixo. Todos esses elementos visam despertar memórias e fazer o corpo dançar.

\section{Tempo de amar...}

A morte de centenas de crianças durante o apartheid deixou uma cicatriz profunda no corpo nacional sul-africano. Gravados como tatuagens na pele social, estão seus nomes. Nas pequenas placas de mármores espalhadas num jardim de pedras no museu de Hector Peterson. Também na memória de seus professores, que ficaram para narrar a estória, como faz na literatura Antjie Krog (2009), que se inquieta com a atitude das crianças e dos jovens estudantes de cruzarem a linha que os levaria à morte. Hoje se fala de uma geração perdida, tanto pelas mortes quanto pela falta de estudos e profissionalização, pelos traumas vividos. Em nossa jornada pela África do Sul, também cruzamos com vários sobreviventes, escutamos as suas estórias que brilham e marcam o caminho para os andarilhos e os navegantes desse mundo em mudança. Stone Water é dedicada a todas as crianças que agora são estrelas.

As experiências sul-africanas de caminhar, brincar e dançar junto, simbolizadas na videodança, me permitem promover o corpo ao mesmo status que o pensamento tem no Ocidente. Nesse sentido, argumento que o perdão é possível, não só porque posso pensar, mas também porque posso dançar. Pois o que torna a reconciliação um gesto intencional de segurar as mãos um do outro nesse contexto vem de uma concepção de ser humano em que corpo e mente não estão separados. Uma noção de ser humano umuntu envolve umzim- 
ba (corpo, forma, carne); umoya (respiração, ar, vida); umphefumela (sombra, espírito, alma); amandla (vitalidade, força, energia); inhlizyo (coração, centro das emoções); umqondo (cabeça, cérebro, intelecto); ulwimi (linguagem, fala); ubuntu (humanidade). A qualidade mais importante e o que torna um ser humano é ubuntu. Ubuntu, "motho ke motho ba batho ba, ngabantu de ngumuntu de bangwe/umuntu", também quer dizer que uma pessoa é uma pessoa através de outras pessoas. Não se trata de "Eu penso, logo existo", mas, ao contrário, eu sou um ser humano porque eu pertenço. Eu participo, eu compartilho (Tutu, 2000; Venter, 2004). Uma pessoa com ubuntu está aberta e disponível aos outros, apoia os outros, não se sente ameaçada diante daqueles que são bons e capazes, pois sua autoconfiança vem de saber que pertence a um todo maior que diminui quando os outros são humilhados, torturados, oprimidos ou tratados como se fossem menos do que realmente são (Tutu, 2000). Uma pessoa que nasce na sociedade africana não é apenas um ser social, é parte integral e inseparável de sua comunidade. Cada pessoa, cada indivíduo é parte, é um elo na cadeia vital interligando ativa e passivamente a sua ancestralidade e descendentes. Nesse contexto, a comunidade vem sempre em primeiro lugar. Uma pessoa que é nascida numa comunidade africana sempre fará parte dessa comunidade (Venter, 2004). Grata a todas as pessoas que tornaram a Stone Water possível, agradeço por nos acompanhar nesse caminhar junto, segurar as nossas mãos e nos ensinar a amar o nosso mundo e também as nossas crianças.

\section{Notas:}

A realização deste estudo contou com o apoio financeiro do Programa Reuni/UFSC. 2 Pós-doutora em Dança pela University of Cape Town. Professora Associada do Programa de Pós-Graduação em Educação, do Centro de Ciências da Educação, da Universidade Federal de Santa Catarina.

\section{Referências}

ARENDT, Hannah. A vida do espírito: o pensar, o querer, o julgar. Rio de Janeiro: UFRJ/Relume Dumará, 1992. . Entre o passado e o futuro. São Paulo: Perspectiva, 2000. 
BANES, Sally. Writing Dancing in the Age of Postmodernism. Hanouver/London: Wesleyan University Press, 1994.

BORDWELL, David; THOMPSON, Kristin. Film Art: An Introduction. New York: McGraw-Hill, 2010.

DERRIDA, Jacques. O perdão, a verdade, a reconciliação: qual gênero? In: NASCIMENTO, Evandro. Jacques Derrida: pensar a desconstrução. São Paulo: Estação Liberdade, 2005.

ECLESIASTES. In: A BÍBLIA: tradução ecumênica. São Paulo: Loyola, 1995.

KAEPPLER, Adrienne L. The Mystique of Fieldwork. In: BUCKLAND, Theresa J. (Ed.). Dance in the Field: Theory Methods and Issues in Dance Ethnography. New York: St. Martin's Press, 1999. p. 13-25.

KLEIN, Jennie. Walking in Kuopio. Dance Theatre Journal, Lodon: Laban, v. 23, n. 4, 2010.

KROG, Antjie. Begging to be Black. Cape Town: Random House Struik, 2009.

MANDELA, Nelson Rolihlahla. Long Walk to Freedom. London: Abacus, 1997.

MERLEAU-PONTY, Maurice. A percepção do outro e o diálogo. In: A prosa e o mundo. São Paulo: Cosak \& Naify, 2002. p. 165-180. - A dúvida de Cézanne. In: . O olho e o espírito: seguido de "A linguagem indireta e as vozes do silêncio" e "A dúvida de Cézanne". São Paulo: Cosak \& Naify, 2004. p. 123-142.

PINK, Sarah. Doing Visual Ethnography. London: Sage, 2001.

TUTU, Desmond. No Future without Forgiveness. London/Sidney/Auckland/ Johannesburg: Rider, 2000. 244 p.

VENTER, Elza. The Notion of Ubuntu and Communalism in African Educational Discourse. Studies in Philosophy and Education, Netherlands: Kluwer Academic Publishers, v. 23, n. 2/3, p. 149-160, Mar./May 2004.

Recebido em 31/05/2012

Aceite em 30/06/2012 